\title{
Comparison of platinum combination re-challenge therapy and docetaxel monotherapy in non-small cell lung cancer patients previously treated with platinum-based chemoradiotherapy
}

Hisao Imai ${ }^{1,7^{*}}$, Kyoichi Kaira ${ }^{1,8}$, Keita Mori $^{2}$, Akira Ono ${ }^{1}$, Hiroaki Akamatsu' ${ }^{1}$, Tetsuhiko Taira ${ }^{1}$, Reiko Yoshino ${ }^{5}$, Hirotsugu Kenmotsu', Jun-ichi Saitoh ${ }^{9}$, Hideyuki Harada ${ }^{3}$, Tateaki Naito ${ }^{1}$, Haruyasu Murakami ${ }^{1}$, Yoshio Tomizawa ${ }^{5}$, Masana Matsuura ${ }^{6}$, Ryusei Saito ${ }^{5}$, Takashi Nakajima ${ }^{4}$, Masanobu Yamada ${ }^{7}$ and Toshiaki Takahashi ${ }^{1}$

\begin{abstract}
Platinum-based chemoradiotherapy (CRT) is a standard front-line treatment for locally advanced non-small cell lung cancer (NSCLC). However, no clinical trials have compared the efficacy and toxicity of platinum combination and docetaxel as subsequent re-challenge chemotherapies after cancer recurrence following CRT. This study aimed to evaluate the efficacy and toxicity of platinum combination chemotherapy versus docetaxel monotherapy in NSCLC patients previously treated with platinum-based CRT.

From September 2002 to December 2009, at three participating institutions, 24 patients with locally advanced NSCLC, who had previously received platinum-based CRT, were treated with platinum combination re-challenge therapy, whereas 61 received docetaxel monotherapy. We reviewed their medical charts to evaluate patient characteristics and data regarding treatment response, survival, and toxicity.

The response rates were $16.7 \%$ and $6.6 \%$ in the platinum combination chemotherapy and docetaxel monotherapy groups, respectively $(p=0.09)$, whereas disease control rates were $58.3 \%$ and $57.4 \%$, respectively $(p=0.82)$. Progression-free survival was similar between the two groups (median, 4.2 vs. 2.3 months; hazard ratio $[H R]=0.81$; $95 \%$ confidence interval $[\mathrm{Cl}]=0.51-1.29 ; p=0.38$ ), as was overall survival (median, 16.5 vs. 13.0 months; $\mathrm{HR}=0.82$; $95 \% \mathrm{Cl}=0.47-1.41 ; p=0.47$ ). The incidence and severity of toxicity was also similar between the two groups. Hematological toxicity, particularly leukopenia and neutropenia, was more frequent in the docetaxel group. Our results indicated that platinum combination re-challenge was equivalent to docetaxel for relapsed patients previously treated with platinum-based CRT.
\end{abstract}

Keywords: Platinum combination; Docetaxel; Non-small cell lung cancer; Chemoradiotherapy; Recurrence; Second-line chemotherapy

\footnotetext{
* Correspondence: m06701014@gunma-u.ac.jp

${ }^{1}$ Division of Thoracic Oncology, Shizuoka Cancer Center, 1007

Shimonagakubo, Nagaizumi, Suntou-gun, Shizuoka 411-8777, Japan

${ }^{7}$ Department of Medicine and Molecular Science, Gunma University Graduate

School of Medicine, 3-39-15, Showa-machi, Maebashi, Gunma 371-8511,

Japan

Full list of author information is available at the end of the article
} 


\section{Introduction}

In 2012, lung cancer was the most frequently diagnosed cancer and the leading cause of cancer-related death in men worldwide (Torre et al. 2015). Non-small cell lung cancer (NSCLC) accounts for $85 \%$ of all lung cancer cases, and more than $50 \%$ of NSCLC patients are diagnosed at advanced disease stages (Siegel et al. 2012). Stage III NSCLC is a heterogeneous disease, likely due to the involvement of different nodes, and as such, it is difficult to treat. Sause et al. reported that adding chemotherapy to radiotherapy prolonged survival (Sause et al. 2000). A recent meta-analysis concluded that concurrent chemoradiotherapy (CRT) was state-of-the art treatment for patients with NSCLC (Auperin et al. 2010), and CRT is currently recommended as the standard first-line treatment for locally advanced NSCLC. The median survival of patients with stage III NSCLC has recently been updated from 12 to 23.3 months in phase III trials (Hanna et al. 2008; Vokes et al. 2007). Although concurrent CRT provides a high rate of tumor response (60-70\%), it does not necessarily lead to a cure. In fact, recent phase III trials of concurrent CRT have reported that two-thirds of patients who experience complete or partial response eventually relapse (Segawa et al. 2010; Yamamoto et al. 2010) and ultimately require systemic therapy.

The current curative treatment of previously untreated locoregional disease frequently involves the use of chemotherapy, usually platinum-based, either as an adjuvant after surgery or concomitantly with high-dose radiotherapy (Auperin et al. 2006). In theory, patients who are initially treated with a platinum agent as part of CRT and then relapse may have been left with a clonal population of platinum-resistant malignant cells (Huisman et al. 2000). Therefore, when subsequently re-treated with platinum-based chemotherapy, they may not achieve the same degree of benefit as those who receive platinumbased chemotherapy as their first-line treatment.

Several cytotoxic agents, such as docetaxel and pemetrexed, are useful as second- or third-line treatments for NSCLC. Docetaxel is a standard second-line chemotherapy regimen that is most widely used in Japan. A randomized phase III study comparing docetaxel and best supportive care demonstrated better overall survival (OS) for docetaxel patients (7.5 vs. 4.6 months, $p=0.047$ ) (Shepherd et al. 2000). Since then, a number of other cytotoxic agents have been introduced as effective agents for second-line treatment (Fossella et al. 2000; Hanna et al. 2004; Ramlau et al. 2006). However, the impact of previous chemotherapy on the efficacy of subsequent chemotherapy has yet to be established. The effectiveness of re-administration of cytotoxic anti-cancer drugs has been reported in patients with small-cell lung cancer who respond to initial treatment with the same drugs (Ebi et al. 1997). Similarly, more recent studies have shown that in NSCLC patients who respond to an initial treatment with gefitinib, the disease could be successfully controlled by re-challenging with gefitinib (Kurata et al. 2004; Tomizawa et al. 2010).

However, the efficacy and safety of re-challenging with platinum-based therapy for relapsed patients who initially receive platinum-based CRT is unknown. Since many other salvage drugs are available, the administration of cisplatin- or carboplatin-based salvage therapy is uncommon, and potential cumulative toxicity with platinum re-challenging (e.g. neurotoxicity) is of concern. Furthermore, the use of platinum-based regimens as second-line treatment has not been shown to improve survival rates in randomized trials. To our knowledge, there is no prospective research comparing the survival benefit between platinum-based regimen re-challenge and docetaxel monotherapy. Additionally, no clinical trial has compared the efficacy and toxicity of platinum combination re-challenge therapy and docetaxel monotherapy as subsequent chemotherapy after cancer recurrence following CRT. In fact, evidence for patients with post-CRT cancer recurrence is lacking. This study aimed to evaluate the efficacy and toxicity of platinum combination chemotherapy in comparison with docetaxel monotherapy in NSCLC patients who had previously been treated with platinum-based CRT.

\section{Patients and methods Patients}

We retrospectively reviewed 85 consecutive patients with locally advanced NSCLC who had previously received platinum-based concurrent CRT at three institutions (Shizuoka Cancer Center, National Hospital Organization Nishi-gunma Hospital, and Gunma University Hospital) between September 2002 and December 2009. Of these, 24 were subsequently treated with platinum combination chemotherapy at relapse, whereas 61 received docetaxel monotherapy. Both time-to-event variables were censored by the study cut-off date (April 1, 2014). The eligibility criteria for this study were: (1) histologically or cytologically proven NSCLC; (2) age of $\leq 75$ years at the time of front-line CRT; (3) Eastern Cooperative Oncology Group Performance Status (ECOG PS) of 0-2; (4) treated with curative thoracic radiotherapy of greater than 50 Gy concurrent with platinum-doublet chemotherapy; and (5) subsequently treated with platinum combination chemotherapy or docetaxel monotherapy after cancer recurrence. The following baseline pretreatment demographic and prognostic information was obtained: sex, age, ECOG PS, clinical stage at the time of recurrence, histology, smoking history, number 
of treatment cycles, response to prior CRT, interval between the final administration of the previous chemotherapy and the start of subsequent chemotherapy, radiation dosage, and prior chemotherapy regimen. All patients underwent systematic evaluation and standardized staging procedures before the start of treatment. Clinical stage was assigned based on the results of physical examination, chest radiography, computed tomography (CT) scans of the chest and abdomen, CT or magnetic resonance imaging of the brain, and bone scintigraphy or positron emission tomography. $\mathrm{Pa}-$ tients with distant metastases before receiving chemoradiotherapy were excluded from this analysis. Tumor stage was determined according to the classification system of the International Association for the Study of Lung Cancer. The histologic classification of a tumor was based on the World Health Organization criteria (Travis et al. 1999). This study was approved by the institutional review board of each participating institution. Written informed consent was not required owing to the study's retrospective design.

\section{Treatment methods}

Radiotherapy was administered using 6- or 10-MV X-rays in 2-Gy fractions five times weekly. All patient treatment plans were designed using a three-dimensional treatment planning system. The gross tumor volume was delineated according to nodal involvement determined by CT. The clinical target volume was defined and contoured with 5-10 $\mathrm{mm}$ around the gross tumor volume and outlines of the regional lymph node areas, i.e., the ipsilateral hilum and the mediastinum. Planning target volume (PTV) 1 was comprised of the clinical target volume plus a 5-10 mm margin, whereas PTV2 included the gross tumor volume plus a $10-\mathrm{mm}$ margin. An additional margin was added if necessary. Beam shaping was performed using a multileaf collimator. The standard of practice was to prescribe a treatment dose of 60 Gy to PTV2 and 40 Gy to PTV1. Other objectives were to restrict the relative volume of normal lung irradiation at a dose of $>20$ Gy (V20) to $\leq 35 \%$, and to restrict the maximum spinal cord dose to $<44 \mathrm{~Gy}$. The dose was prescribed to the isocenter.

\section{Subsequent chemotherapy after post-CRT recurrence}

The decision to re-treat with a platinum-based chemotherapy and the choice of subsequent platinum-based chemotherapy regimen were determined by the treating physician. For patients re-treated with docetaxel monotherapy, docetaxel was administered at a dose of $60 \mathrm{mg} / \mathrm{m}^{2} /$ week given every three weeks or longer. For both regimens, treatment changes such as dose reduction, dose skipping, or dose delay were decided by the treating physician.

\section{Assessment of efficacy and toxicity and statistical analysis}

Radiographic tumor responses were evaluated according to the Response Evaluation Criteria in Solid Tumors (Therasse et al. 2000). The Common Terminology Criteria for Adverse Events v3.0 was used to evaluate acute adverse events until four weeks after the final chemotherapy administration or a patient's death. All statistical analyses were performed using JMP, version 9.0, for Windows (SAS Institute, Cary, NC, USA). OS was calculated from the start of the first chemotherapy cycle to the date of death from any cause or that of the last follow-up. OS was estimated using the KaplanMeier method. The Fisher's exact test and the Wilcoxon rank-sum test were used to compare the mean values of the variables between the two groups. Statistical significance was set at $p<0.05$.

\section{Results}

Patient characteristics

Patient characteristics are shown in Table 1. Of the enrolled patients, 24 received platinum combination chemotherapy as their subsequent chemotherapy, whereas 61 received docetaxel monotherapy. Among those treated with platinum combination chemotherapy, six received cisplatin, and 18 carboplatin. There were no statistically significant differences between the two groups in terms of sex, age, PS, clinical stage at the time of recurrence, histology, smoking history, number of treatment cycles, time since prior CRT, radiation dosage, or prior chemotherapy regimen. However, the re-challenge group tended to have more patients with adenocarcinoma than the docetaxel group, and there were statistically significant differences between the two groups in terms of response to prior CRT and number of regimens after progression following second-line chemotherapy. After progressing past second-line chemotherapy, 23 of the 85 patients did not receive further chemotherapy. The chemotherapy regimens provided after the second-line regimen are shown in Table 2. The median follow-up time at the study censoring date was 27.3 months (range, 7.4-105.9 months).

\section{Objective tumor response to therapy and survival}

Objective tumor response is shown in Table 3. The differences in the response rate (RR) and disease-control rate between the two groups were not statistically significant ( $\mathrm{RR}, p=0.09$; disease-control rate, $p=0.82$ ).

Progression-free survival (PFS) was similar between the platinum combination therapy group and the docetaxel monotherapy group (median, 4.2 vs. 2.3 months; hazard ratio $[\mathrm{HR}]=0.81 ; 95 \%$ confidence interval $[\mathrm{CI}]=$ $0.51-1.29 ; p=0.38$ ) (Figure 1A). OS was also similar between the two groups (median, 16.5 vs. 13.0 months; $\mathrm{HR}=0.82 ; 95 \% \mathrm{CI}=0.47-1.41 ; p=0.47$ ) (Figure 1B). 
Table 1 Baseline patient characteristics at the beginning of chemotherapy by treatment arm

\begin{tabular}{llll}
\hline Characteristics & $\begin{array}{l}\text { Platinum } \\
\text { combination } \\
\text { therapy }(n=24)\end{array}$ & $\begin{array}{l}\text { Docetaxel } \\
\text { monotherapy }\end{array}$ & $p$ \\
$(n=61)$ & value
\end{tabular}

Sex

Male

22

Female

2

Age, median (range), years

$63.5(46-74)$

Performance status

$$
\begin{aligned}
& 0 \\
& 1 \\
& 2
\end{aligned}
$$$$
\text { III }
$$

Histology

\begin{tabular}{|c|c|}
\hline \multirow{2}{*}{\multicolumn{2}{|c|}{$\begin{array}{l}\text { Clinical stage at the time of recurrence } \\
\text { III }\end{array}$}} \\
\hline & \\
\hline IV & 16 \\
\hline \multicolumn{2}{|l|}{ Histology } \\
\hline Adenocarcinoma & 14 \\
\hline Squamous cell carcinoma & 8 \\
\hline Large cell carcinoma & 2 \\
\hline Others & 0 \\
\hline \multicolumn{2}{|l|}{ EGFR mutation status } \\
\hline Mutant & 3 \\
\hline Wild-type & 8 \\
\hline Unknown & 13 \\
\hline \multicolumn{2}{|l|}{ Smoking history } \\
\hline Current or former & 20 \\
\hline Never & 3 \\
\hline Unknown & 1 \\
\hline $\begin{array}{l}\text { Number of treatment cycles, } \\
\text { median (range) }\end{array}$ & $2(1-6)$ \\
\hline \multicolumn{2}{|c|}{ Response to prior chemoradiotherapy } \\
\hline Complete response & 1 \\
\hline Partial response & 10 \\
\hline Stable disease & 10 \\
\hline Progressive disease & 3 \\
\hline Time since prior chemoradiotl & herapy \\
\hline
\end{tabular}

Clinical stage at the time of recurrence

Mutant

Wild-type

Unknown

Smoking history

Current or former

Never

Unknown

\begin{tabular}{|c|c|}
\hline \multicolumn{2}{|c|}{ Clinical stage at the time of recurrence } \\
\hline III & 8 \\
\hline IV & 16 \\
\hline \multicolumn{2}{|l|}{ Histology } \\
\hline Adenocarcinoma & 14 \\
\hline Squamous cell carcinoma & 8 \\
\hline Large cell carcinoma & 2 \\
\hline Others & 0 \\
\hline \multicolumn{2}{|l|}{ EGFR mutation status } \\
\hline Mutant & 3 \\
\hline Wild-type & 8 \\
\hline Unknown & 13 \\
\hline \multicolumn{2}{|l|}{ Smoking history } \\
\hline Current or former & 20 \\
\hline Never & 3 \\
\hline Unknown & 1 \\
\hline $\begin{array}{l}\text { Number of treatment cycles, } \\
\text { median (range) }\end{array}$ & $2(1-6)$ \\
\hline \multicolumn{2}{|c|}{ Response to prior chemoradiotherapy } \\
\hline Complete response & 1 \\
\hline Partial response & 10 \\
\hline Stable disease & 10 \\
\hline Progressive disease & 3 \\
\hline
\end{tabular}

Number of treatment cycles, 2 (1-6) median (range)

Response to prior chemoradiotherapy

\begin{tabular}{|c|c|}
\hline \multicolumn{2}{|c|}{ Clinical stage at the time of recurrence } \\
\hline III & 8 \\
\hline IV & 16 \\
\hline \multicolumn{2}{|l|}{ Histology } \\
\hline Adenocarcinoma & 14 \\
\hline Squamous cell carcinoma & 8 \\
\hline Large cell carcinoma & 2 \\
\hline Others & 0 \\
\hline \multicolumn{2}{|l|}{ EGFR mutation status } \\
\hline Mutant & 3 \\
\hline Wild-type & 8 \\
\hline Unknown & 13 \\
\hline \multicolumn{2}{|l|}{ Smoking history } \\
\hline Current or former & 20 \\
\hline Never & 3 \\
\hline Unknown & 1 \\
\hline $\begin{array}{l}\text { Number of treatment cycles, } \\
\text { median (range) }\end{array}$ & $2(1-6)$ \\
\hline \multicolumn{2}{|c|}{ Response to prior chemoradiotherapy } \\
\hline Complete response & 1 \\
\hline Partial response & 10 \\
\hline Stable disease & 10 \\
\hline Progressive disease & 3 \\
\hline Time since prior chemoradioth & herapy \\
\hline
\end{tabular}

\section{$<6$ months}

\section{$\geq 6$ months}

Radiation dosage, median (range), Gy

Prior chemotherapy regimen

$\begin{array}{ll}\text { CDDP }+ \text { VNR } & 5 \\ \text { CDDP }+ \text { S1 } & 7 \\ \text { CBDCA }+ \text { PTX } & 6 \\ \text { Others } & 6\end{array}$

10
14
$60(58-70)$

$52 \quad 0.40^{\mathrm{a}}$

$0<0.05^{\mathrm{a}}$

45
19

0

Pror

$\begin{array}{ll}20 & 0.17^{a} \\ 16 & \\ 17 & \\ 8 & \end{array}$

Table 1 Baseline patient characteristics at the beginning of chemotherapy by treatment arm (Continued)

Number of regimens after progression following second-line chemotherapy

0/1/2/ $\geq 3 \quad 11 / 10 / 3 / 0 \quad 12 / 22 / 12 / 15$

Median (range) $\quad 1(0-2) \quad 1(0-6) \quad<0.05^{\mathrm{b}}$

Abbreviations: EGFR, epidermal growth factor receptor; CDDP, cisplatin; VNR, vinorelbine; CBDCA, carboplatin; PTX, paclitaxel.

${ }^{a}$ Fisher's exact test; ${ }^{b}$ Wilcoxon rank-sum test.

Patients in each treatment group were further stratified based on relapse-free survival (RFS). In the platinum combination therapy group, 10 patients had an RFS of $<6$ months, and 14 had an RFS of $\geq 6$ months. Among the platinum combination therapy patients with
an RFS of $<6$ months, one had a partial response (PR); gressive disease (PD). Among the platinum combination therapy patients with an RFS of $\geq 6$ months, three had a PR; six had SD, and five had PD. The median PFS for the platinum combination therapy patients with an RFS of $<6$ months and $\geq 6$ months was 3.6 and 5.6 months, respectively (log-rank, $p=0.07$ ) (Figure $2 \mathrm{~A}$ ). Furthermore, the corresponding median OS for these patients was 16.5 and 25.3 months, respectively (log-rank, $p=0.55$ ) (Figure 2B). In the docetaxel monotherapy group, 19 patients had an RFS of $<6$ months, and 42 had an RFS of $\geq 6$ months. Among the docetaxel monotherapy patients with an RFS of $<6$ months, one had a PR; eight had SD, and seven had PD, whereas among those with an RFS of $\geq 6$ months, two had a complete response/ PR; 23 had SD, and 17 had PD. The median PFS for the docetaxel monotherapy patients with an RFS of $<6$ months

Table 2 Chemotherapy regimens used after progression following second-line chemotherapy

\begin{tabular}{|c|c|c|c|c|}
\hline & \multicolumn{2}{|c|}{$\begin{array}{l}\text { Platinum combination } \\
\text { therapy }\end{array}$} & \multicolumn{2}{|c|}{$\begin{array}{l}\text { Docetaxel } \\
\text { monotherapy }\end{array}$} \\
\hline & $\begin{array}{l}\text { Third- } \\
\text { line }\end{array}$ & $\begin{array}{l}\geq \text { Fourth- } \\
\text { line }\end{array}$ & $\begin{array}{l}\text { Third- } \\
\text { line }\end{array}$ & $\begin{array}{l}\geq \text { Fourth- } \\
\text { line }\end{array}$ \\
\hline \multicolumn{5}{|l|}{ EGFR-TKI } \\
\hline Gefitinib & 1 & 1 & 11 & 5 \\
\hline Erlotinib & 2 & 0 & 5 & 7 \\
\hline \multicolumn{5}{|l|}{ Single agent } \\
\hline Docetaxel & 0 & 1 & - & 1 \\
\hline Pemetrexed & 2 & 0 & 2 & 3 \\
\hline Amrubicin & 2 & 1 & 8 & 11 \\
\hline Gemcitabine & 0 & 1 & 16 & 8 \\
\hline S1 & 0 & 0 & 5 & 12 \\
\hline Others & 2 & 0 & 1 & 5 \\
\hline Platinum combination & 3 & 0 & 0 & 5 \\
\hline Investigational agent & 0 & 0 & 1 & 4 \\
\hline
\end{tabular}

Abbreviations: EGFR-TKI, epidermal growth factor receptor tyrosine kinase inhibitor. 
Table 3 Objective tumor response

\begin{tabular}{llll}
\hline & $\begin{array}{l}\text { Platinum combination } \\
\text { therapy }(\mathbf{n = 2 4 )} \\
\mathbf{n}(\%)\end{array}$ & $\begin{array}{l}\text { Docetaxel } \\
\text { monotherapy } \\
(\mathbf{n = 6 1 )} \mathbf{n}(\%)\end{array}$ & $p$ value* \\
\hline Complete response & $0(0)$ & $1(1.6)$ & 0.30 \\
Partial response & $4(16.7)$ & $3(4.9)$ & \\
Stable disease & $10(41.7)$ & $31(50.8)$ & \\
Progressive disease & $9(37.5)$ & $24(39.3)$ & \\
Not evaluable & $1(4.1)$ & $2(3.3)$ & 0.09 \\
Response rate $(\%)$ & 16.7 & 6.6 & 0.82 \\
$\begin{array}{l}\text { Disease control } \\
\text { rate }{ }^{\mathrm{a}}(\%)\end{array}$ & 58.3 & 57.4 & \\
\hline
\end{tabular}

*Fisher's exact test.

${ }^{a}$ Complete response + partial response + stable disease.

and $\geq 6$ months was 2.2 and 2.8 months, respectively (log-rank, $p=0.08$ ) (Figure 3A). Furthermore, the corresponding median $\mathrm{OS}$ for these patients was 12.0 and 16.3 months, respectively (log-rank, $p=0.14$ ) (Figure 3B). The differences in median PFS and OS among the four sub-groups (platinum combination therapy patients with an RFS of $\geq 6 /<6$ months and docetaxel monotherapy patients with an RFS of $\geq 6 /<6$ months) were not statistically significant.

\section{Toxicity}

A summary of the toxicities observed in both groups is shown in Table 4. Hematological toxicities, particularly leukopenia and neutropenia, tended to be more frequent in the docetaxel monotherapy group. However, there were no statistically significant differences between the two groups in grade 3 and above leukopenia $(p=0.06)$ or grade 3 and above neutropenia $(p=0.08)$. The incidences of other toxicities did not differ between the two groups. Discontinuation of chemotherapy related to toxicity occurred in one patient in the platinum combination therapy group (grade 4 leukopenia) and five patients in the docetaxel monotherapy group (grade 3 interstitial pneumonitis in two patients, grade 3 febrile neutropenia in one patient, grade 3 paralytic ileus in one patient, and grade 3 edema in one patient). All grade $\geq 3$ adverse events related to platinum-based chemotherapy, such as nausea, vomiting, nephrotoxicity, neurotoxicity, and fatigue, were not observed in more than $5 \%$ of the patients. There were no treatment-related deaths in either group.

\section{Discussion}

Platinum-based doublet chemotherapy prolongs survival and improves quality of life in patients with a PS of 0-2. Chemotherapy should be initiated while the patient maintains a good PS (Reck et al. 2014). Such a recommendation is based on findings from previous trials on metastatic diseases, including both primary metastatic and relapsed diseases after local therapies.
Platinum resistance is often a concern when secondline treatment for relapsed NSCLC is initiated after failure of first-line treatment (Huisman et al. 2000). As previously discussed, prior exposure to platinum as part of CRT might reduce the likelihood of response to subsequent platinum therapy. In fact, known molecular mechanisms of platinum resistance may be responsible for the worse outcomes observed in patients previously treated with platinum-based CRT (Cosaert and Quoix 2002). The $10 \%$ RR observed by Paramanathan et al. in patients who were re-challenged with platinum-based chemotherapy at disease relapse, supports the platinumresistance hypothesis (Paramanathan et al. 2013).

However, a small retrospective study of patients treated with first-line chemotherapy and re-challenged on relapse with the same chemotherapy (usually platinum-based) showed a response rate of $29 \%$ and superior survival compared to those treated with a second-line agent (docetaxel). Such a result suggests that in certain cases, re-challenging with the first-line agents, rather than switching to a different drug, is a reasonable strategy (Nagano et al. 2010). Furthermore, if this study limits its enrolled patients to only responders as the previous study did, it might have the same outcome. However, no phase III trials have been conducted in a secondline setting to evaluate the value of platinum doublets, including newer agents such as taxanes and pemetrexed, for the treatment of NSCLC. Recently, two meta-analyses evaluated pemetrexed- and docetaxelbased doublets as second-line treatments and showed an advantage in RR and PFS compared to treatment with single agents (Qi et al. 2012a; Qi et al. 2012b). In these meta-analyses, only two trials included platinum agents, and only one of these studies enrolled patients who had previously been treated with platinum agents. This recent study by Ardizzoni et al. was a pooled analysis of two randomized phase II trials comparing carboplatin/pemetrexed and pemetrexed alone to treat stage IV NSCLC pre-treated with platinum agents (Ardizzoni et al. 2012). Overall, the RR significantly increased from $9 \%$ to $15 \%$, and PFS from 3 to 3.9 months in the combination arm, but the OS was similar in second-line treatment. Our study showed a $16.7 \%$ tumor RR for the platinum combination therapy group, which was comparable to the $R R$ reported by the above-mentioned study.

Our results indicated that the treatment protocol for relapsed NSCLC in patients previously treated with platinum-based CRT might require a re-evaluation. A recent meta-analysis showed that similar one-year survival rates were achieved with non-platinum-based doublets as first-line therapy (D'Addario et al. 2005). Published treatment guidelines from the American Society of Clinical Oncology suggest that non-platinum-based 



Figure 1 Progression-free survival (PFS) and overall survival (OS) by treatment arm. (A) PFS: platinum combination, median PFS $=4.2$ months; docetaxel monotherapy, median PFS = 2.3 months. (B) OS: platinum combination, median OS = 16.5 months; docetaxel monotherapy, median OS $=13.0$ months.

doublets might provide an alternative option to certain groups of patients (Azzoli et al. 2011). Given the higher toxicities experienced by patients receiving platinumbased doublet therapy and the similar survival rates for both platinum and non-platinum-based doublet therapy, it would be reasonable to advocate a change in treatment protocol for this particular group of patients. Alternatively, these patients could be treated with a non-platinum single agent such as pemetrexed, docetaxel, or erlotinib, depending on the clinical situation.

Many previous prospective trials and retrospective studies have not sufficiently documented patients' prior treatment history, including platinum exposure. Moreover, although patients who relapse after prior CRT are commonly seen in clinical practice, recent trials of firstline chemotherapy for metastatic disease have excluded them. Given the potential for treatment resistance, a history of prior platinum exposure should be collected from patients enrolled in future trials of chemotherapy for metastatic disease. Although we previously reported that re-challenge with platinum combination chemotherapy was effective and safe for relapsed patients after postoperative cisplatin-based adjuvant chemotherapy for resected NSCLC (Imai et al. 2013), our current report suggests that non-platinum based agents might be considered in NSCLC patients who relapse after platinum-based CRT. Although both studies consider prior treatment history, the optimal treatment 

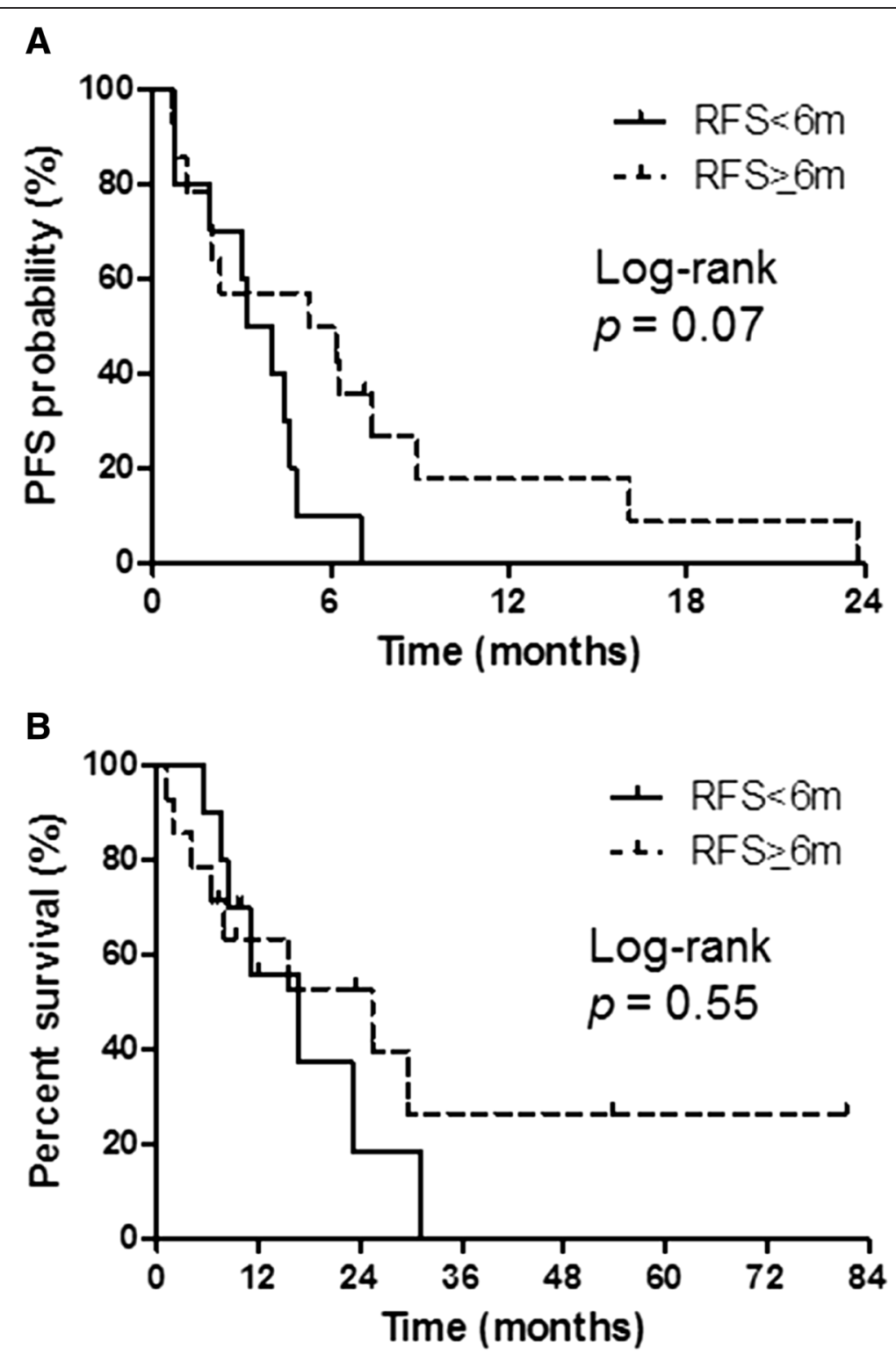

Figure 2 Progression-free survival (PFS) and overall survival (OS) according to relapse-free survival (RFS) in the platinum combination therapy group. (A) PFS: RFS $<6$ months, median PFS $=3.6$ months; RFS $\geq 6$ months, median PFS $=5.6$ months. (B) OS: RFS $<6$ months, median OS $=16.5$ months; RFS $\geq 6$ months, median OS $=25.3$ months.

following CRT may differ from the one following postoperative adjuvant chemotherapy.

In the present study, although 23 of the 85 patients did not receive subsequent chemotherapy after progressing past second-line chemotherapy, many others did. The increased number of treatment regimens currently used following progression after second-line chemotherapy might be the result of more active compounds, such as gefitinib, erlotinib, docetaxel, pemetrexed, amrubicin, gemcitabine, and S-1, available for the treatment of advanced NSCLC. In fact, a number of different compounds were used to treat our patients, as shown in Table 2. It might be of importance to carefully examine the correlation between epidermal growth factor receptor tyrosine kinase inhibitor (EGFR-TKI) responders or additional therapies and survival. However, statistical analysis might be challenging to perform because the number of patients receiving EGFR-TKI is relatively small. Furthermore, response to EGFR-TKI reportedly depends on patients' ethnicity, sex, smoking history, and histological type according to a previous study on patients receiving gefitinib based on clinical background (Mitsudomi et al. 2006). In addition, although analysis of EGFR mutation status is routinely performed for NSCLC patients currently, it was not previously, which might affect patient stratification for EGFR-TKI treatment. 


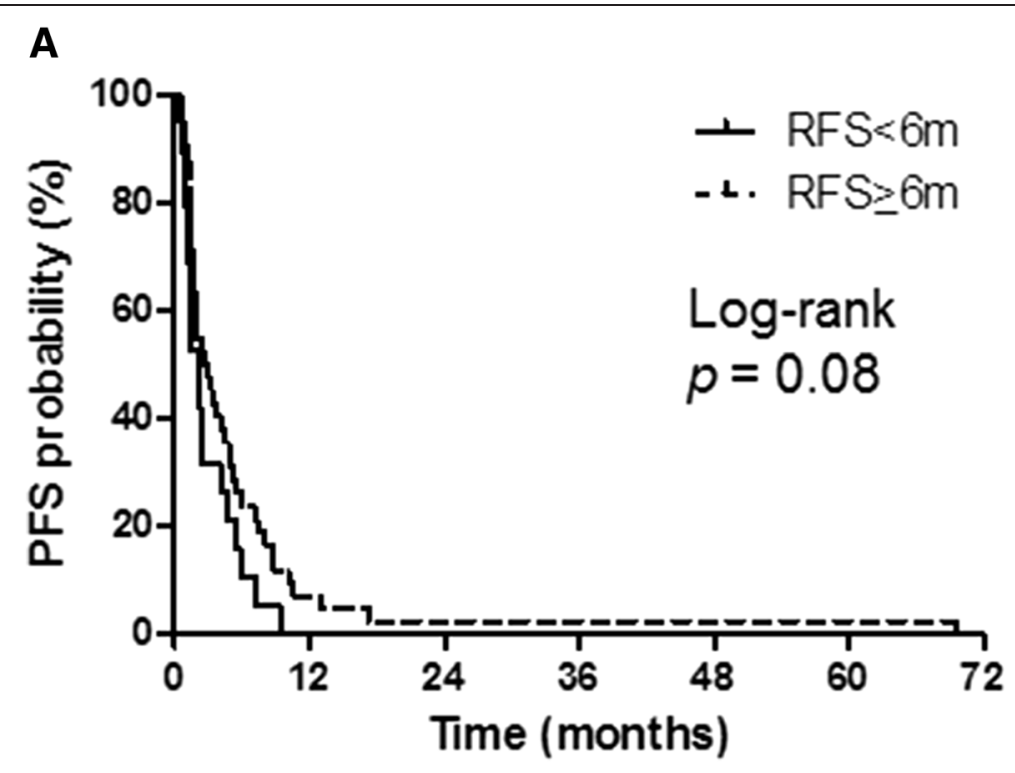

B

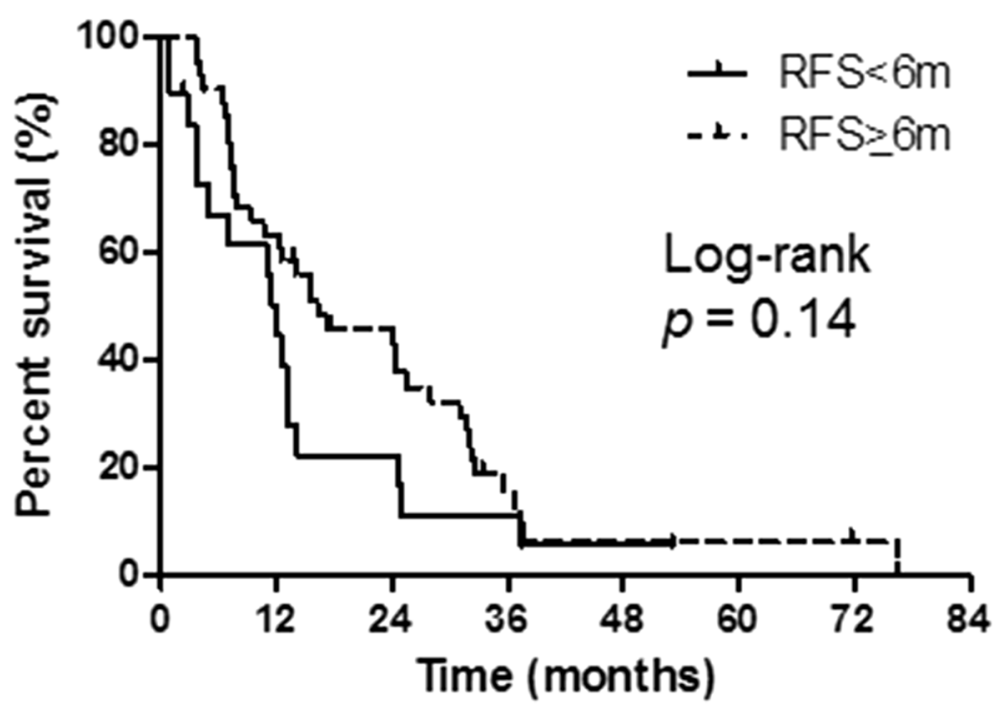

Figure 3 Progression-free survival (PFS) and overall survival (OS) according to relapse-free survival (RFS) in the docetaxel monotherapy group. (A) PFS: RFS <6 months, median PFS = 2.2 months; RFS $\geq 6$ months, median PFS = 2.8 months. (B) OS: RFS $<6$ months, median OS = 12.0 months; RFS $\geq 6$ months, median OS $=16.3$ months.

Table 4 CTCAE grade $\geq 3$ adverse events observed in more than $5 \%$ of patients

\begin{tabular}{|c|c|c|c|c|c|c|c|}
\hline & \multicolumn{3}{|c|}{ Platinum combination therapy $(n=24)$} & \multicolumn{3}{|c|}{ Docetaxel monotherapy $(n=61)$} & \multirow[b]{2}{*}{$p$ value } \\
\hline & Grade 3 & Grade 4 & Total (\%) & Grade 3 & Grade 4 & Total (\%) & \\
\hline Leukocytopenia & 8 & 2 & $10(41.6)$ & 30 & 9 & $39(63.9)$ & 0.06 \\
\hline Neutropenia & 8 & 6 & $14(58.3)$ & 16 & 28 & $44(72.1)$ & 0.08 \\
\hline Anemia & 3 & 0 & $3(12.5)$ & 2 & 0 & $2(3.3)$ & 0.12 \\
\hline Febrile neutropenia & 2 & 0 & $2(8.3)$ & 6 & 0 & $6(9.8)$ & 0.82 \\
\hline Anorexia & 1 & 0 & $1(4.2)$ & 5 & 0 & $5(8.2)$ & 0.49 \\
\hline Infection & 1 & 0 & $1(4.2)$ & 3 & 0 & $3(4.9)$ & 0.88 \\
\hline
\end{tabular}


The interval from first- to second-line chemotherapy was quite variable in both of our study groups. Considering only patients whose RFS was more than six months, the median PFS was 5.6 months and 2.8 months $(p=0.30)$, and the median OS was 25.3 months and 16.3 months $(p=0.44)$ in the platinum combination and docetaxel groups, respectively. Although these differences were not significant, there was a trend toward longer PFS and OS in this group. It is known that the treatment efficacy for metastatic cervical cancer is similarly low to that seen in our study if platinum-based CRT has been given less than six months before treatment (Monk et al. 2009). Due to the small number of patients in our study with an RFS of less than six months, these results might not be significantly different. The fact that the median PFS was worse for patients relapsing within six months of prior platinum-based CRT could relate to the more aggressive nature of relapsed disease or to a potential resistance to chemotherapy. Given the retrospective nature of this study, we could not determine the causative mechanism behind these results, and future prospective research is needed.

Patients who were re-challenged with platinum combination and those receiving docetaxel monotherapy had similar grades and incidences of toxicity, suggesting that the cumulative toxicity of platinum might be absent. In particular, toxicities such as hearing impairment, neurotoxicity, renal dysfunction, and allergic reactions caused by repeated use of platinum combination chemotherapy re-challenge were not notable. In the docetaxel group, however, hematological toxicities, especially leukopenia and neutropenia, were more frequent. A possible reason for this finding might be that the reported grade of adverse event was the worst value observed, and patients receiving docetaxel continued their treatment until PD.

This study has several limitations. First, it was a retrospective analysis, and the toxicities might have been underestimated. Reducing, skipping, or delaying the planned chemotherapy was allowed at the discretion of the attending physician. To minimize this potential bias, all consecutive patients treated at our institutes were included in the analysis, and the patients' original charts were thoroughly reviewed. Second, the sample size of our study was small. Nonetheless, we believe that the results of the present investigation are worthwhile because this small sample size is indicative of the relatively small population of patients who relapse after platinum-based CRT. Finally, the sample size of the two groups in this study was markedly different, but the patients' demographic data were well-balanced.

\section{Conclusion}

We did not find platinum combination re-challenge therapy to be superior in efficacy for relapsed patients previously treated with platinum-based CRT, suggesting that if an NSCLC patient relapses after receiving platinum-based CRT, it is not necessary to favor the use of platinum combination chemotherapy. To our knowledge, this is the first study to evaluate and compare the efficacy and safety of platinum combination re-challenge therapy and docetaxel monotherapy in NSCLC patients previously treated with platinum-based CRT. Although the results of our investigation might contribute to a better understanding of the clinical benefit of platinum combination chemotherapy re-challenge after NSCLC recurrence, future trials comparing platinum and non-platinum chemotherapy following relapse after CRT are needed to help guide clinical practice and recommendations.

\section{Competing interests}

The authors declare that they have no competing interests.

\section{Authors' contributions}

$\mathrm{HI}, \mathrm{KM}, \mathrm{RY}$, and JS developed the initial research question and performed data analysis. $\mathrm{HI}$ and $\mathrm{KK}$ wrote the original manuscript. $\mathrm{HI}, \mathrm{KK}, \mathrm{KM}, \mathrm{AO}, \mathrm{HA}, \mathrm{T}$, $R Y, H K, J S, H H, T N, H M, Y T, M M, R S, T N, M Y$, and TT made all revisions to the manuscript. All authors read and approved the final manuscript.

\section{Acknowledgements}

We wish to thank Ms. Mutsumi Yamazaki, Ms. Fumiko Sakurai, Dr. Kazushige Wakuda, Dr. Shunichi Matsumoto, Dr. Noriaki Sunaga, Dr. Takeshi Hisada, and Dr. Masahiro Endo for their assistance in preparing this manuscript.

\section{Author details}

${ }^{1}$ Division of Thoracic Oncology, Shizuoka Cancer Center, 1007

Shimonagakubo, Nagaizumi, Suntou-gun, Shizuoka 411-8777, Japan. ${ }^{2}$ Clinical Trial Coordination Office, Shizuoka Cancer Center, 1007 Shimonagakubo, Nagaizumi, Suntou-gun, Shizuoka 411-8777, Japan. ${ }^{3}$ Division of Radiation Oncology, Shizuoka Cancer Center, 1007 Shimonagakubo, Nagaizumi, Suntou-gun, Shizuoka 411-8777, Japan. ${ }^{4}$ Division of Diagnostic Pathology, Shizuoka Cancer Center, 1007 Shimonagakubo, Nagaizumi, Suntou-gun, Shizuoka 411-8777, Japan. ${ }^{5}$ Department of Respiratory Medicine, National Hospital Organization Nishigunma Hospital, 2854 Kanai, Shibukawa, Gunma 377-8511, Japan. ${ }^{6}$ Department of Radiology, National Hospital Organization Nishigunma Hospital, 2854 Kanai, Shibukawa, Gunma 377-8511, Japan. 7 Department of Medicine and Molecular Science, Gunma University Graduate School of Medicine, 3-39-15, Showa-machi, Maebashi, Gunma 371-8511, Japan. ${ }^{8}$ Department of Oncology Clinical Development, Gunma University Graduate School of Medicine, 3-39-15, Showa-machi, Maebashi, Gunma 371-8511, Japan. 'Department of Radiation Oncology, Gunma University Graduate School of Medicine, 3-39-15, Showa-machi, Maebashi, Gunma 371-8511, Japan.

Received: 26 January 2015 Accepted: 16 March 2015

Published online: 31 March 2015

\footnotetext{
References

Ardizzoni A, Tiseo M, Boni L, Vincent AD, Passalacqua R, Buti S, Amoroso D, Camerini A, Labianca R, Genestreti G, Boni C, Ciuffreda L, Di Costanzo F, de Marinis F, Crino L, Santo A, Pazzola A, Barbieri F, Zilembo N, Colantonio I, Tibaldi C, Mattioli R, Cafferata MA, Camisa R, Smit EF (2012) Pemetrexed versus pemetrexed and carboplatin as second-line chemotherapy in advanced non-small-cell lung cancer: results of the GOIRC 02-2006 randomized phase II study and pooled analysis with the NVALT7 trial. J Clin Oncol 30(36):4501-4507, doi:10.1200/JCO.2012.43.6758

Auperin A, Le Pechoux C, Rolland E, Curran WJ, Furuse K, Fournel P, Belderbos J, Clamon G, Ulutin HC, Paulus R, Yamanaka T, Bozonnat MC, Uitterhoeve A, Wang X, Stewart L, Arriagada R, Burdett S, Pignon JP (2010) Meta-analysis of concomitant versus sequential radiochemotherapy in locally advanced non-small-cell lung cancer. J Clin Oncol 28(13):2181-2190, doi:10.1200/ JCO.2009.26.2543
} 
Auperin A, Le Pechoux C, Pignon JP, Koning C, Jeremic B, Clamon G, Einhorn L, Bal D, Trovo MG, Groen HJ, Bonner JA, Le Chevalier T, Arriagada R, Meta-Analysis of Cisplatin/carboplatin based Concomitant Chemotherapy in non-small cell Lung Cancer G (2006) Concomitant radio-chemotherapy based on platin compounds in patients with locally advanced non-small cell lung cancer (NSCLC): a meta-analysis of individual data from 1764 patients. Ann Oncol 17(3):473-483, doi:10.1093/annonc/mdj117

Azzoli CG, Temin S, Aliff T, Baker S Jr, Brahmer J, Johnson DH, Laskin JL, Masters G, Milton D, Nordquist L, Pao W, Pfister DG, Piantadosi S, Schiller JH, Smith R, Smith TJ, Strawn JR, Trent D, Giaccone G, American Society of Clinical O (2011) 2011 Focused Update of 2009 American Society of Clinical Oncology Clinical Practice Guideline Update on Chemotherapy for Stage IV Non-Small-Cell Lung Cancer. J Clin Oncol 29(28):3825-3831, doi:10.1200/JCO.2010.34.2774

Cosaert J, Quoix E (2002) Platinum drugs in the treatment of non-small-cell lung cancer. Br J Cancer 87(8):825-833, doi:10.1038/sj.bjc.6600540

D'Addario G, Pintilie M, Leighl NB, Feld R, Cerny T, Shepherd FA (2005) Platinum-based versus non-platinum-based chemotherapy in advanced non-small-cell lung cancer a meta-analysis of the published literature. J Clin Oncol 23(13):2926-2936, doi:10.1200/JCO.2005.03.045

Ebi N, Kubota K, Nishiwaki Y, Hojo F, Matsumoto T, Kakinuma R, Ohmatsu H, Sekine I, Yokosaki M, Gotoh K, Yamamoto H, Kodama T (1997) Second-line chemotherapy for relapsed small cell lung cancer. Jpn J Clin Oncol 27 (3):166-169

Fossella FV, DeVore R, Kerr RN, Crawford J, Natale RR, Dunphy F, Kalman L, Miller V, Lee JS, Moore M, Gandara D, Karp D, Vokes E, Kris M, Kim Y, Gamza F, Hammershaimb L (2000) Randomized phase III trial of docetaxel versus vinorelbine or ifosfamide in patients with advanced non-small-cell lung cancer previously treated with platinum-containing chemotherapy regimens. The TAX 320 Non-Small Cell Lung Cancer Study Group. J Clin Oncol 18 (12):2354-2362

Hanna N, Shepherd FA, Fossella FV, Pereira JR, De Marinis F, von Pawel J, Gatzemeier U, Tsao TC, Pless M, Muller T, Lim HL, Desch C, Szondy K, Gervais R, Shaharyar A, Manegold C, Paul S, Paoletti P, Einhorn L, Bunn PA Jr (2004) Randomized phase III trial of pemetrexed versus docetaxel in patients with non-small-cell lung cancer previously treated with chemotherapy. J Clin Oncol 22(9):1589-1597, doi:10.1200/JCO.2004.08.163

Hanna N, Neubauer M, Yiannoutsos C, McGarry R, Arseneau J, Ansari R, Reynolds C, Govindan R, Melnyk A, Fisher W, Richards D, Bruetman D, Anderson T, Chowhan N, Nattam S, Mantravadi P, Johnson C, Breen T, White A, Einhorn L, Hoosier Oncology G, Oncology US (2008) Phase III study of cisplatin, etoposide, and concurrent chest radiation with or without consolidation docetaxel in patients with inoperable stage III non-small-cell lung cancer: the Hoosier Oncology Group and U.S. Oncology. J Clin Oncol 26(35):5755-5760, doi:10.1200/JCO.2008.17.7840

Huisman C, Smit EF, Giaccone G, Postmus PE (2000) Second-line chemotherapy in relapsing or refractory non-small-cell lung cancer: a review. J Clin Oncol 18(21):3722-3730

Imai H, Shukuya T, Yoshino R, Muraki K, Mori K, Ono A, Akamatsu H, Taira T,

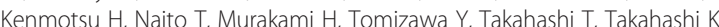
Saito R, Yamamoto N (2013) Efficacy and safety of platinum combination chemotherapy re-challenge for relapsed patients with non-small-cell lung cancer after postoperative adjuvant chemotherapy of cisplatin plus vinorelbine. Chemotherapy 59(4):307-313, doi: 10.1159/000356155

Kurata T, Tamura K, Kaneda H, Nogami T, Uejima H, Asai Go G, Nakagawa K, Fukuoka M (2004) Effect of re-treatment with gefitinib ('Iressa', ZD1839) after acquisition of resistance. Ann Oncol 15(1):173-174

Mitsudomi T, Kosaka T, Yatabe Y (2006) Biological and clinical implications of EGFR mutations in lung cancer. Int J Clin Oncol 11(3):190-198, doi:10.1007/s10147-006-0583-4

Monk BJ, Sill MW, McMeekin DS, Cohn DE, Ramondetta LM, Boardman CH, Benda J, Cella D (2009) Phase III trial of four cisplatin-containing doublet combinations in stage IVB, recurrent, or persistent cervical carcinoma: a Gynecologic Oncology Group study. J Clin Oncol 27(28):4649-4655, doi:10.1200/JCO.2009.21.8909

Nagano T, Kim YH, Goto K, Kubota K, Ohmatsu H, Niho S, Yoh K, Naito Y, Saijo N, Nishiwaki Y (2010) Re-challenge chemotherapy for relapsed non-small-cel lung cancer. Lung Cancer 69(3):315-318

Paramanathan A, Solomon B, Collins M, Franco M, Kofoed S, Francis H, Ball D, Mileshkin L (2013) Patients treated with platinum-doublet chemotherapy for advanced non-small-cell lung cancer have inferior outcomes if previously treated with platinum-based chemoradiation. Clin Lung Cancer 14(5):508-512, doi:10.1016/j.cllc.2013.03.007
Qi WX, Shen Z, Yao Y (2012a) Meta-analysis of docetaxel-based doublet versus docetaxel alone as second-line treatment for advanced non-small-cell lung cancer. Cancer chemotherapy and pharmacology 69 (1):99-106. doi:10.1007/s00280-011-1678-9

Qi WX, Tang LN, He AN, Shen Z, Yao Y (2012b) Effectiveness and safety of pemetrexed-based doublet versus pemetrexed alone as second-line treatment for advanced non-small-cell lung cancer: a systematic review and meta-analysis. Journal of cancer research and clinical oncology 138 (5):745-751. doi:10.1007/s00432-012-1155-9

Ramlau R, Gervais R, Krzakowski M, von Pawel J, Kaukel E, Abratt RP, Dharan B, Grotzinger KM, Ross G, Dane G, Shepherd FA (2006) Phase III study comparing oral topotecan to intravenous docetaxel in patients with pretreated advanced non-small-cell lung cancer. J Clin Oncol 24(18):2800-2807, doi:10.1200/ JCO.2005.03.6491

Reck M, Popat S, Reinmuth N, De Ruysscher D, Kerr KM, Peters S, Group EGW (2014) Metastatic non-small-cell lung cancer (NSCLC): ESMO Clinical Practice Guidelines for diagnosis, treatment and follow-up. Ann Oncol 25(Suppl 3):iii27-39, doi:10.1093/annonc/mdu199

Sause W, Kolesar P, Taylor SI, Johnson D, Livingston R, Komaki R, Emami B, Curran W Jr, Byhardt R, Dar AR, Turrisi A 3rd (2000) Final results of phase III trial in regionally advanced unresectable non-small cell lung cancer: Radiation Therapy Oncology Group, Eastern Cooperative Oncology Group, and Southwest Oncology Group. Chest 117(2):358-364

Segawa Y, Kiura K, Takigawa N, Kamei H, Harita S, Hiraki S, Watanabe Y, Sugimoto K, Shibayama T, Yonei T, Ueoka H, Takemoto M, Kanazawa S, Takata I, Nogami N, Hotta K, Hiraki A, Tabata M, Matsuo K, Tanimoto M (2010) Phase III trial comparing docetaxel and cisplatin combination chemotherapy with mitomycin, vindesine, and cisplatin combination chemotherapy with concurrent thoracic radiotherapy in locally advanced non-small-cell lung cancer: OLCSG 0007. J Clin Oncol 28(20):3299-3306, doi: 10.1200/JCO.2009.24.7577

Shepherd FA, Dancey J, Ramlau R, Mattson K, Gralla R, O'Rourke M, Levitan N, Gressot L, Vincent M, Burkes R, Coughlin S, Kim Y, Berille J (2000) Prospective randomized trial of docetaxel versus best supportive care in patients with non-small-cell lung cancer previously treated with platinum-based chemotherapy. J Clin Oncol 18(10):2095-2103

Siegel R, Naishadham D, Jemal A (2012) Cancer statistics, 2012. CA 62(1):10-29, doi:10.3322/caac.20138

Therasse P, Arbuck SG, Eisenhauer EA, Wanders J, Kaplan RS, Rubinstein L, Verweij J, Van Glabbeke M, van Oosterom AT, Christian MC, Gwyther SG (2000) New guidelines to evaluate the response to treatment in solid tumors. European Organization for Research and Treatment of Cancer, National Cancer Institute of the United States, National Cancer Institute of Canada. J Natl Cancer Inst 92(3):205-216

Tomizawa Y, Fujita Y, Tamura A, Shirai M, Shibata S, Kawabata T, Shibayama T, Fukai S, Kawahra M, Saito R (2010) Effect of gefitinib re-challenge to initial gefitinib responder with non-small cell lung cancer followed by chemotherapy. Lung Cancer 68(2):269-272, doi:10.1016/j.lungcan.2009.06.025

Torre LA, Bray F, Siegel RL, Ferlay J, Lortet-Tieulent J, Jemal A (2015) Global cancer statistics, 2012. CA ..., doi:10.3322/caac.21262

Travis WD, Colby TV, Corrin B, Shimosato Y (1999) Histological typing of lung and pleural tumors, 3rd edn. Springer, Berlin

Vokes EE, Herndon JE 2nd, Kelley MJ, Cicchetti MG, Ramnath N, Neill H, Atkins JN, Watson DM, Akerley W, Green MR, Cancer, Leukemia Group B (2007) Induction chemotherapy followed by chemoradiotherapy compared with chemoradiotherapy alone for regionally advanced unresectable stage III Non-small-cell lung cancer: Cancer and Leukemia Group B. J Clin Oncol 25 (13):1698-1704, doi:10.1200/JCO.2006.07.3569

Yamamoto N, Nakagawa K, Nishimura Y, Tsujino K, Satouchi M, Kudo S, Hida T, Kawahara M, Takeda K, Katakami N, Sawa T, Yokota S, Seto T, Imamura F, Saka H, Iwamoto Y, Semba H, Chiba Y, Uejima H, Fukuoka M (2010) Phase III study comparing second- and third-generation regimens with concurrent thoracic radiotherapy in patients with unresectable stage III non-small-cell lung cancer: West Japan Thoracic Oncology Group WJTOG0105. J Clin Oncol 28(23):3739-3745, doi:10.1200/JCO.2009.24.5050 